\title{
Environmental Policy And Firm Relocation: The Case Of U.S.-Mexico
}

Patrik T. Hultberg (E-mail: hultberg@uwyo.edu), University of Wyoming

\begin{abstract}
The paper studies the effect of stringent environmental policy on domestic firms' location decisions, especially in the context of a bilateral trade agreement. The main variables included are market size, trade barriers, and fixed costs of establishing abroad. The results show that parameter assumption in the inverse demand function matter. In addition, changes in model variables yield both intuitive and some less intuitive results. For example, predictions on firm movement following economic integration are not as clear as might be expected. The results are discussed in the context of U.S.-Mexico economic integration.
\end{abstract}

\section{Introduction}

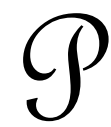

olicy makers, industrialists, and environmentalists all express concern about the impact of more stringent environmental policies on the competitiveness of the domestic industry and, in particular, about the possibility that a domestic producer may relocate plants to countries with less stringent environmental regulations. These concerns are precipitated by changes in both U.S. levels of environmental control and trade and investment patterns. For example, between 1973 and 1982 manufacturing industries in the U.S. nearly doubled their expenditures for pollution control from $\$ 3$ billion to just under $\$ 6$ billion (Leonard, 1984) and from 1973 to 1994 U.S. pollution abatement operating costs increased more than eight times (U.S. Bureau of the Census). At the same time the U.S. has moved from a position of approximate trade balances to operating with trade deficits. Many businessmen and policymakers attribute this deficit to the rising production costs resulting from strict environmental standards, while empirically the results are less clear. ${ }^{1}$

A summary of the empirical literature concludes that the evidence regarding environmental policies' effect on firm movement is mixed. Empirical studies indicate that dirty industries are more prevalent in developing countries which may be due to specialization in pollution-intensive industries (Lucas et al., 1992, Low and Yeats, 1992). Also, the share of dirty-industry exports in industrialized countries has been reduced while the share of such exports has increased for some developing countries (Low and Yeats, 1992). Such evidence does not, in itself, necessarily support the conclusion that environmental cost differences lead to relocation, only that such an explanation is consistent with the empirical trends. However, as discussed by Beghin et al. (1994), most studies do not find strong evidence that environmental regulations per se lead to low competitiveness and firm relocation. The main reason for this result may be that the magnitude of environmental costs in total costs is presently small for most industries. For example, Low (1992) claims that the weighted average ratio of environmental costs (pollution abatement and control costs) to output in the U.S. was $0.54 \%$, with the highest ratio being $3 \%$ for the cement industry in 1988. However, the author also points out that this may not cover the full cost to U.S. industry of pollution control.

Readers with comments or questions are encouraged to contact the authors via email.

Despite the weak evidence on the role of environmental costs on plant location, several theoretical models have been built to explore this linkage. The theoretical research on plant location differs from standard industrial

\footnotetext{
${ }^{1}$ Of course much concern has been expressed about differential labor costs as well.
} 
pollution models in environmental economics. The standard assumption in such models is constant returns to scale, each firm has a given number of plants in a fixed location, and optimality occurs when the marginal cost of pollution control equates the marginal benefit. In contrast, theories of industrial plant location assume that in addition to these continuous plant decisions, there is a possibility of discrete location choices, such as whether or not to locate plants to another country. In our case, this could be due to a unilateral emissions tax being imposed on domestic firms thus raising production costs leading to loss in competitiveness. If costs rise substantially, it may become impossible for domestic plants to compete and they may take advantage of low environmental standards abroad by moving production.

Early theoretical research on plant location considers a game in which in the early stages possible firm entrants view government action and then in the later stage decide where to locate depending upon, for example, environmental policies (e.g. Markusen et al. 1993, Ulph 1994). In these kinds of models, plant location can be a function of environmental policy, but plants are footloose in the sense that they locate after government decisions. More recently, Motta and Thisse (1994) consider an alternative framework, which assumes that plants are initially located in their home countries when environmental regulation changes. In a Cournot setting, where market size only affects the slope of their inverse demand function, these authors explore the impact on firm location when model parameters are changed. The main conclusion from their study is that plant relocation is less likely (compared to e.g. Markusen et al. 1993) since establishing a foreign subsidiary involves fixed costs for the domestic firm that are already incurred (i.e. a sunk cost) for its domestic plant.

Although our approach follows that of Motta and Thisse (1994), we consider an important modification to their modeling framework. By generalizing their inverse demand function, we obtain different equilibrium outputs that affect the choice of firm location after changing environmental policy. Among the new results are (1) the choice of parameters in the inverse demand function does matter. The main impact of changing parameter assumptions in Motta and Thisse (1994) is to heighten the importance of both market size and environmental policy differences across countries. For example, relatively small environmental cost differentials may lead to sharp reductions in exports, and perhaps even complete shut down of the domestic firm at small market sizes. (2) Changes in parameter values (tariff rates, fixed costs, relative market sizes) under the generalized framework yield many intuitive results, which increases our confidence in the model. For example, lower tariff rates make it less likely that a firm would become multinational and lower fixed costs of establishing plants abroad makes it more likely that firms would move production to a foreign country. (3) When these intuitive results are applied to cases of economic integration, they show the difficulty of predicting the effect of firm movement. In fact, economic integration efforts is often characterized by a combination of both lower tariffs and lower costs of moving production abroad, so the effect on firm movement is ambiguous. Thus our modifications are not only realistic extensions to the Motta and Thisse (1994) framework, but also allow for an opportunity to employ the model when analyzing the environmental provisions of a bilateral trade treaty, such as the U.S.-Mexico North American Free Trade Agreement (NAFTA) on industry relocation.

\section{The model and initial results}

Similar to Motta and Thisse (1994), we consider a two-country, two-firm economy where presently firm 1 is located in country A and firm 2 is located in country B. The two firms produce a homogeneous good and are already established in their country of origin. All fixed costs associated with home country production are sunk and do not affect the cost of production for the domestic plants. In order to observe the impact of a change in country A's environmental policy on the location decision of firm 1, we assume that the location decision of firm 2 as well as the environmental policy of country B is fixed. We then explore whether a strict environmental policy in country A leads firm 1 to continue to supply both markets, A and B, from its domestic plant. Alternatively, firm 1 may instead decides to establish a subsidiary in country B to supply each market locally or, perhaps, decides to shut down its original domestic plant and relocate to country B serving both markets from this new plant.

Each country $i(i=A, B)$ has an inverse demand function given by $p_{i}=a\left(S_{i}\right)-b\left(S_{i}\right) Q_{i}$, where $Q_{i}$ is total output sold in country $i, p_{i}$ is the market clearing price, and $S_{i}$ is a parameter corresponding to the market size of country $i$ (e.g. population size or level of income). Variable (marginal) production costs are assumed constant and identical across countries prior to enactment of more stringent environmental policies in A. When country A enacts a stricter environmental policy its marginal cost, $c_{A}+e$, rises and $c_{A}+e \geq c_{B}$. When a firm exports it incurs a trading cost per unit 
of output equal to $t$, where $1 \geq t \geq 0$. If firm 1 decides to establish a plant in country B it incurs a fixed set-up cost that is independent of output but depends on the number of markets served. Thus fixed cost can be viewed as including both the actual costs of setting up production abroad (build a plant, establish a distribution network) and the added costs due to uncertainty regarding such things as threat of nationalization and profit repatriation. Also, these fixed costs cannot be discounted to zero over time, thus there might be continuous fixed costs in doing business abroad: the threat of nationalization or the necessity to build and maintain infrastructure.

The model is solved as a standard Cournot competition game and below we give the main results before any assumptions are imposed on $\mathrm{a}\left(\mathrm{S}_{\mathrm{i}}\right)$ and $\mathrm{b}\left(\mathrm{S}_{\mathrm{i}}\right)$. Three location configurations are considered: (1) Firm 1 has a plant in country A and may export to country B but incurs no set-up cost. This case is denoted (A,0). (2) Firm 1 opens a subsidiary plant in B to replace its export market only. This case is denoted (A,B) and firm 1 incurs a set-up cost equal to $F_{B}$. (3) Firm 1 eliminates production in $A$ and establishes a plant in $B$ to serve both markets. This configuration $(0, B)$ results in set-up cost $F_{A}+F_{B}$, where $F_{B}>F_{A}$, due to either economies of scale or the possibility of recycling its domestic facility abroad (salvage value). For these three location choices, the profit functions for firm 1 are:

(1) $\Pi_{1}(\mathrm{~A}, 0)=\left[\mathrm{a}\left(\mathrm{S}_{\mathrm{A}}\right)-\mathrm{b}\left(\mathrm{S}_{\mathrm{A}}\right)\left(\mathrm{q}_{1 \mathrm{~A}}+\mathrm{q}_{2 \mathrm{~A}}\right)\right] \mathrm{q}_{1 \mathrm{~A}}+\left[\mathrm{a}\left(\mathrm{S}_{\mathrm{B}}\right)-\mathrm{b}\left(\mathrm{S}_{\mathrm{B}}\right)\left(\mathrm{q}_{1 \mathrm{~B}}+\mathrm{q}_{2 \mathrm{~B}}\right)\right] \mathrm{q}_{1 \mathrm{~B}}-\left(\mathrm{c}_{\mathrm{A}}+\mathrm{e}\right) \mathrm{q}_{1 \mathrm{~A}}-\left(\mathrm{c}_{\mathrm{A}}+\mathrm{e}+\mathrm{t}\right) \mathrm{q}_{1 \mathrm{~B}}$

(2) $\Pi_{1}(\mathrm{~A}, \mathrm{~B})=\left[\mathrm{a}\left(\mathrm{S}_{\mathrm{A}}\right)-\mathrm{b}\left(\mathrm{S}_{\mathrm{A}}\right)\left(\mathrm{q}_{1 \mathrm{~A}}+\mathrm{q}_{2 \mathrm{~A}}\right)\right] \mathrm{q}_{1 \mathrm{~A}}+\left[\mathrm{a}\left(\mathrm{S}_{\mathrm{B}}\right)-\mathrm{b}\left(\mathrm{S}_{\mathrm{B}}\right)\left(\mathrm{q}_{1 \mathrm{~B}}+\mathrm{q}_{2 \mathrm{~B}}\right)\right] \mathrm{q}_{1 \mathrm{~B}}-\left(\mathrm{c}_{\mathrm{A}}+\mathrm{e}\right) \mathrm{q}_{1 \mathrm{~A}}-\mathrm{c}_{\mathrm{B}} \mathrm{q}_{1 \mathrm{~B}}-\mathrm{F}_{\mathrm{B}}$

(3) $\Pi_{1}(0, B)=\left[a\left(S_{A}\right)-b\left(S_{A}\right)\left(q_{1 A}+q_{2 A}\right)\right] q_{1 A}+\left[a\left(S_{B}\right)-b\left(S_{B}\right)\left(q_{1 B}+q_{2 B}\right)\right] q_{1 B}-\left(c_{B}+t\right) q_{1 A}-c_{B} q_{1 B}-F_{A}-F_{B}$

For firm 2 in country B the profit function is always of the same form:

(4) $\Pi_{2}(0, B)=\left[a\left(S_{A}\right)-b\left(S_{A}\right)\left(q_{1 A}+q_{2 A}\right)\right] q_{2 A}+\left[a\left(S_{B}\right)-b\left(S_{B}\right)\left(q_{1 B}+q_{2 B}\right)\right] q_{2 B}-\left(c_{B}+t\right) q_{2 A}-c_{B} q_{2 B}$

The terms within square brackets are the prices in country A and B, respectively, $\mathrm{c}$ represents the constant marginal cost, $\mathrm{e}$ is the environmental cost, and $\mathrm{t}$ is the trade cost, constant and the same in either direction. Maximizing these profit functions with respect to the relevant quantity yields the firms' reaction functions that are solved simultaneously to find the optimal quantities and optimal profit levels for the three location configurations. Below we assume that $\mathrm{c}_{\mathrm{A}}=\mathrm{c}_{\mathrm{B}}=0$ so that the only difference is the higher environmental cost (e) in country A. For each location choice, a strategy for firm $j(j=1,2)$ is a pair of quantities $\left(q_{j A}, q_{j B}\right)$ of the homogeneous good sold in countries A and B. Below we give these optimal pair of quantities for each location choice, as well as the optimal profit function.

Case $(\mathbf{A}, \mathbf{0})$ : The equilibrium outputs sold by each firm $\mathrm{j}(\mathrm{j}=1,2)$ in country $\mathrm{i}(\mathrm{i}=\mathrm{A}, \mathrm{B})$ are:

$$
\begin{array}{ll}
\mathrm{q}^{*}{ }_{1 \mathrm{~A}}=\left[1 / 3 \mathrm{~b}\left(\mathrm{~S}_{\mathrm{A}}\right)\right]\left[\mathrm{a}\left(\mathrm{S}_{\mathrm{A}}\right)-2 \mathrm{e}+\mathrm{t}\right] & \mathrm{q}^{*}{ }_{2 \mathrm{~A}}=\left[1 / 3 \mathrm{~b}\left(\mathrm{~S}_{\mathrm{A}}\right)\right]\left[\mathrm{a}\left(\mathrm{S}_{\mathrm{A}}\right)+\mathrm{e}-2 \mathrm{t}\right] \\
\mathrm{q}^{*}{ }_{1 \mathrm{~B}}=\left[1 / 3 \mathrm{~b}\left(\mathrm{~S}_{\mathrm{B}}\right)\right]\left[\mathrm{a}\left(\mathrm{S}_{\mathrm{B}}\right)-2 \mathrm{e}-2 \mathrm{t}\right] & \mathrm{q}^{*}{ }_{2 \mathrm{~B}}=\left[1 / 3 \mathrm{~b}\left(\mathrm{~S}_{\mathrm{B}}\right)\right]\left[\mathrm{a}\left(\mathrm{S}_{\mathrm{B}}\right)+\mathrm{e}+\mathrm{t}\right]
\end{array}
$$

Substituting optimal quantities into equation (1) gives an optimal profit level of

$$
\text { (5) } \Pi^{*}(\mathrm{~A}, 0)=\left[1 / 9 \mathrm{~b}\left(\mathrm{~S}_{\mathrm{A}}\right)\right]\left[\mathrm{a}\left(\mathrm{S}_{\mathrm{A}}\right)-2 \mathrm{e}+\mathrm{t}\right]^{2}+\left[1 / 9 \mathrm{~b}\left(\mathrm{~S}_{\mathrm{B}}\right)\right]\left[\mathrm{a}\left(\mathrm{S}_{\mathrm{B}}\right)-2 \mathrm{e}-2 \mathrm{t}\right]^{2}
$$

Note that if $\mathrm{e}>(1 / 2)\left[a\left(\mathrm{~S}_{\mathrm{A}}\right)+\mathrm{t}\right]$ then firm 1 will not sell in country $A$, and if $\mathrm{e}>(1 / 2)\left[a\left(\mathrm{~S}_{\mathrm{B}}\right)-2 \mathrm{t}\right]$ then firm 1 would not export to country $\mathrm{B}$ (since $\mathrm{q}^{*}{ }_{1 \mathrm{~A}}=0$ and $\mathrm{q}^{*}{ }_{1 \mathrm{~B}}=0$, respectively). If both of these conditions are satisfied simultaneously, then it is never profitable for firm 1 to produce (firm 2 is the only seller in both markets) and firm 1 profit is $\Pi_{1} *(\mathrm{~A}, 0)=0$. In this case firm 1 is faced with the option of moving all production to country B or simply to desist.

Case (A, B): The equilibrium outputs sold by each firm in each market are:

$$
\begin{array}{lr}
\mathrm{q}^{*}{ }_{1 \mathrm{~A}}=\left[1 / 3 \mathrm{~b}\left(\mathrm{~S}_{\mathrm{A}}\right)\right]\left[\mathrm{a}\left(\mathrm{S}_{\mathrm{A}}\right)-2 \mathrm{e}+\mathrm{t}\right] & \mathrm{q}^{*}{ }_{2 \mathrm{~A}}=\left[1 / 3 \mathrm{~b}\left(\mathrm{~S}_{\mathrm{A}}\right)\right]\left[\mathrm{a}\left(\mathrm{S}_{\mathrm{A}}\right)+\mathrm{e}-2 \mathrm{t}\right] \\
\mathrm{q}^{*}{ }_{1 \mathrm{~B}}=\left[1 / 3 \mathrm{~b}\left(\mathrm{~S}_{\mathrm{B}}\right)\right]\left[\mathrm{a}\left(\mathrm{S}_{\mathrm{B}}\right)\right] & \mathrm{q}^{*}{ }_{2 \mathrm{~B}}=\left[1 / 3 \mathrm{~b}\left(\mathrm{~S}_{\mathrm{B}}\right)\right]\left[\mathrm{a}\left(\mathrm{S}_{\mathrm{B}}\right)\right]
\end{array}
$$

The optimal profit earned by firm 1 from equation (2) is: 


$$
\text { (6) } \Pi^{*}(\mathrm{~A}, \mathrm{~B})=\left[1 / 9 \mathrm{~b}\left(\mathrm{~S}_{\mathrm{A}}\right)\right]\left[\mathrm{a}\left(\mathrm{S}_{\mathrm{A}}\right)-2 \mathrm{e}+\mathrm{t}\right]^{2}+\left[1 / 9 \mathrm{~b}\left(\mathrm{~S}_{\mathrm{B}}\right)\right]\left[\mathrm{a}\left(\mathrm{S}_{\mathrm{B}}\right)\right]^{2}-\mathrm{F}_{\mathrm{B}}
$$

We see that in order for firm 1 to sell in country B, the relative size of B must be large compared to the fixed costs required for setting up a plant in that country. The requirement for positive profits in country $\mathrm{A}$ is the same as in $(\mathrm{A}, 0)$. Thus when firm 1 decides whether to remain in A or shift some production over to $\mathrm{B}$, it would compare $\left[1 / 9 b\left(S_{B}\right)\right]\left[a\left(S_{B}\right)-2 e-2 t\right]^{2}$ to $\left[1 / 9 b\left(S_{B}\right)\right]\left[a\left(S_{B}\right)\right]^{2}-F_{B}$. If the latter is larger, firm 1 would move from configuration $(A, 0)$ to $(A, B)$, ignoring the possibility of the extreme case of complete relocation, $(0, B)$. As is expected, this relocation is less likely to occur as $F_{B}$ increases, as e decreases, and as $t$ decreases.

Case $3(\mathbf{0}, \mathbf{B})$ : The equilibrium outputs for both firms producing only in country B are:

$$
\begin{array}{ll}
\mathrm{q}^{*}{ }_{1 \mathrm{~A}}=\left[1 / 3 \mathrm{~b}\left(\mathrm{~S}_{\mathrm{A}}\right)\right]\left[\mathrm{a}\left(\mathrm{S}_{\mathrm{A}}\right)-\mathrm{t}\right] & \mathrm{q}^{*}{ }_{2 \mathrm{~A}}=\left[1 / 3 \mathrm{~b}\left(\mathrm{~S}_{\mathrm{A}}\right)\right]\left[\mathrm{a}\left(\mathrm{S}_{\mathrm{A}}\right)-\mathrm{t}\right] \\
\mathrm{q}^{*}{ }_{1 \mathrm{~B}}=\left[1 / 3 \mathrm{~b}\left(\mathrm{~S}_{\mathrm{B}}\right)\right]\left[\mathrm{a}\left(\mathrm{S}_{\mathrm{B}}\right)\right] & \mathrm{q}^{*}{ }_{2 \mathrm{~B}}=\left[1 / 3 \mathrm{~b}\left(\mathrm{~S}_{\mathrm{B}}\right)\right]\left[\mathrm{a}\left(\mathrm{S}_{\mathrm{B}}\right)\right]
\end{array}
$$

With firm 1 equilibrium optimal profits from equation (3) being:

$$
\text { (7) } \Pi^{*}(0, B)=\left[1 / 9 b\left(S_{A}\right)\right]\left[a\left(S_{A}\right)-t\right]^{2}+\left[1 / 9 b\left(S_{B}\right)\right]\left[a\left(S_{B}\right)\right]^{2}-F_{A}-F_{B}
$$

Note that in order for firm 1 to move from configuration $(A, B)$ to $(0, B)$ it would compare its profit levels in country $A$ in the two cases. Firm 1 relocates to $(0, B)$ if $\left[1 / 9 b\left(S_{A}\right)\right]\left[a\left(S_{A}\right)-t\right]^{2}-F_{B}$ is greater than $\left[1 / 9 b\left(S_{A}\right)\right]\left[a\left(S_{A}\right)-2 e+t\right]^{2}$, given that firm 1 already has a plant in country $\mathrm{B}$ that serves $\mathrm{B}$. This movement of firm 1's production is then less likely if $\mathrm{F}_{\mathrm{A}}$ increases or if the environmental policy is less strict.

These partial observations do not provide the entire story behind firm 1's location choices; to determine where firm 1 will locate (allowing for discrete choices), we compare the four optimal profit conditions:

$$
\begin{aligned}
& \Pi^{*}(\mathrm{~A}, 0)=\left[1 / 9 \mathrm{~b}\left(\mathrm{~S}_{\mathrm{A}}\right)\right]\left[\mathrm{a}\left(\mathrm{S}_{\mathrm{A}}\right)-2 \mathrm{e}+\mathrm{t}\right]^{2}+\left[1 / 9 \mathrm{~b}\left(\mathrm{~S}_{\mathrm{B}}\right)\right]\left[\mathrm{a}\left(\mathrm{S}_{\mathrm{B}}\right)-2 \mathrm{e}-2 \mathrm{t}\right]^{2} \\
& \Pi^{*}{ }_{1}(\mathrm{~A}, \mathrm{~B})=\left[1 / 9 \mathrm{~b}\left(\mathrm{~S}_{\mathrm{A}}\right)\right]\left[\mathrm{a}\left(\mathrm{S}_{\mathrm{A}}\right)-2 \mathrm{e}+\mathrm{t}\right]^{2}+\left[1 / 9 \mathrm{~b}\left(\mathrm{~S}_{\mathrm{B}}\right)\right]\left[\mathrm{a}\left(\mathrm{S}_{\mathrm{B}}\right)\right]^{2}-\mathrm{F}_{\mathrm{B}} \\
& \Pi^{*}(0, \mathrm{~B})=\left[1 / 9 \mathrm{~b}\left(\mathrm{~S}_{\mathrm{A}}\right)\right]\left[\mathrm{a}\left(\mathrm{S}_{\mathrm{A}}\right)-\mathrm{t}\right]^{2}+\left[1 / 9 \mathrm{~b}\left(\mathrm{~S}_{\mathrm{B}}\right)\right]\left[\mathrm{a}\left(\mathrm{S}_{\mathrm{B}}\right)\right]^{2}-\mathrm{F}_{\mathrm{A}}-\mathrm{F}_{\mathrm{B}} \\
& \Pi^{*}{ }_{1}(0,0)=0
\end{aligned}
$$

The main difference from Motta and Thisse (1994) arises as we solve this model for three different inverse demand functions to explore how the results are leveraged by functional form. The general inverse demand function, $\mathrm{p}_{\mathrm{i}}=\mathrm{a}\left(\mathrm{S}_{\mathrm{i}}\right)-\mathrm{b}\left(\mathrm{S}_{\mathrm{i}}\right) \mathrm{Q}_{\mathrm{i}}$ (where $\left.\mathrm{Q}_{\mathrm{i}}=\mathrm{q}_{1 \mathrm{i}}+\mathrm{q}_{2 \mathrm{i}}\right)$, is parameterized by letting $\mathrm{a}\left(\mathrm{S}_{\mathrm{i}}\right)=1$ or $\mathrm{S}_{\mathrm{i}}$, and $\mathrm{b}\left(\mathrm{S}_{\mathrm{i}}\right)=1$ or $1 / \mathrm{S}_{\mathrm{i}}$ giving us three specific cases: (1) $a\left(S_{i}\right)=1$ and $b\left(S_{i}\right)=1 / S_{i},(2) a\left(S_{i}\right)=S_{i}$ and $b\left(S_{i}\right)=1$, and (3) $a\left(S_{i}\right)=S_{i}$ and $b\left(S_{i}\right)=1 / S_{i}$. In case (3) we basically assume that an increase in market size both shifts out the demand curve and makes it more elastic. In our discussion of the optimal location choice below, we focus on the last case, but we briefly discuss the other two as well. In particular, case (1) is identical to Motta and Thisse (1994) so we need to point out differences and similarities between it and the more general case.

\section{Optimal location choice}

To address the optimal location choice for firm 1 initially located in country A we face a myriad of cases and parameter values, all of which will influence the quantitative results for optimal location configurations. Consequently we must make some choices: the first step is to compare the three inverse demand functions under some base case scenario, assume that $t=0.3 ; S_{A}=S_{B}$ (same market size); $F_{A}=0 ; F_{B}=1$. A graph is constructed that shows e on the horizontal axis and $S_{B}$ on the vertical axis. Again, in all simulation $c_{B}$ is assumed to be zero and equal to $c_{A}$ to highlight the effect of environmental cost (e). The base case assumes that the fixed cost of building a plant in country B is the same whether one or two markets are served. Consider figure 1, where inverse demand is given by $p_{i}=1-\left(1 / S_{i}\right) Q_{i}$, we see that when the markets are relatively small (say $S_{A}=S_{B}=3$ ) firm 1 will never invest abroad as profits from producing in country B never outweigh the fixed cost. As country A's environmental regulation becomes more stringent, firm 1 continually loses competitiveness with respect to firm $2\left(\delta \Pi{ }_{1}(\mathrm{~A}, \mathrm{O}) /\right.$ $\delta \mathrm{e}<0$ ), so that its sales in both markets fall as e rises leading first to a ceasing of exports to country $\mathrm{B}$ and later to 
complete shut down. ${ }^{2}$ As both countries' market size increases (moving up the $S_{B}$-axis) firm 1 eventually establishes a subsidiary in country B. The large market in country B justifies the fixed cost; that is, at that level of demand the fixed cost is outweighed by lower marginal cost (no e). In fact, for sufficiently high e, firm 1 completely relocates to country B and exports back to country A. In this case the lower marginal cost outweigh both the fixed cost and the trade cost back to country A.
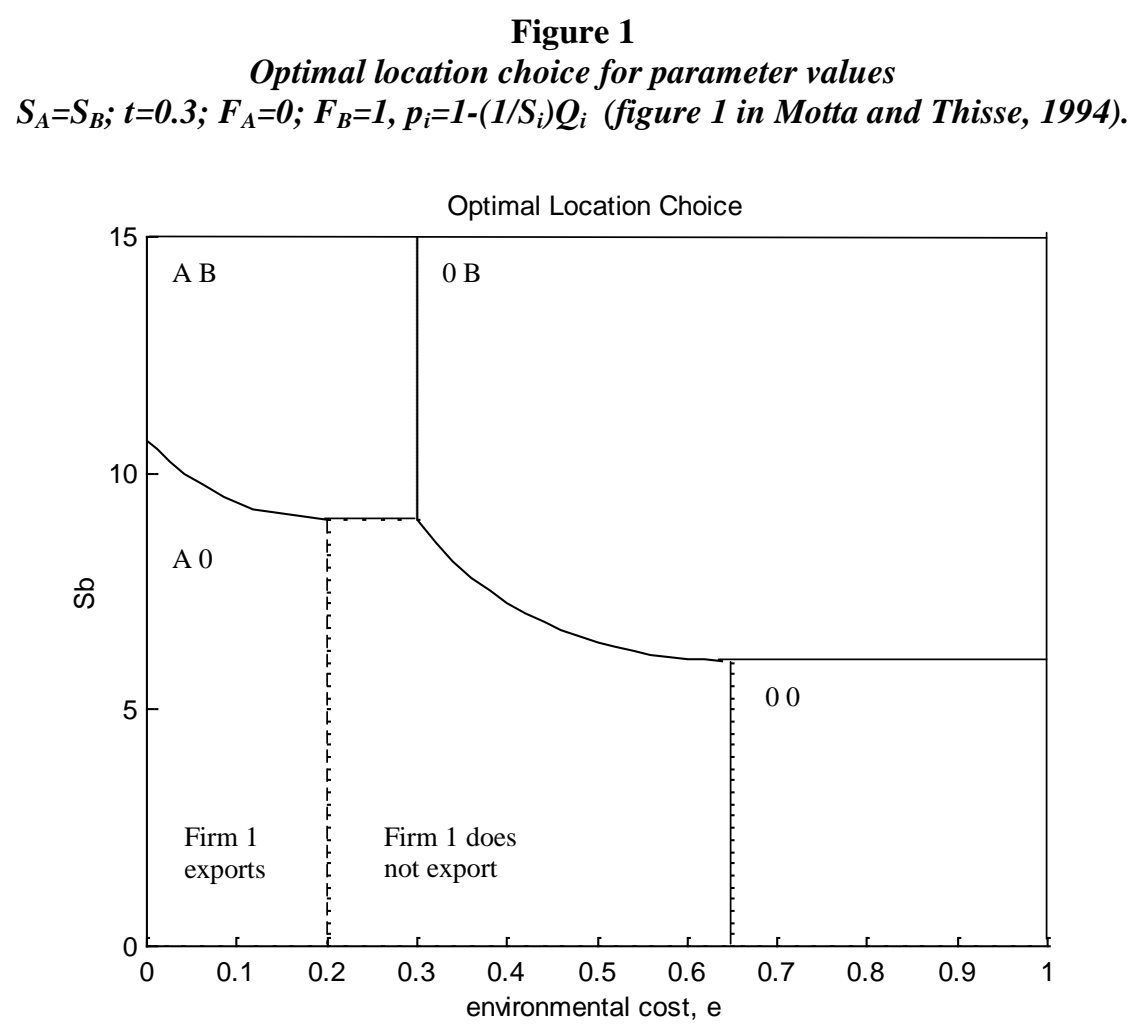

As figure 1 is a reproduction of Motta and Thisse (1994, figure 1), it is only when we assume the inverse demand curve to take the form of either $\mathrm{p}_{\mathrm{i}}=\mathrm{S}_{\mathrm{i}}-\mathrm{Q}_{\mathrm{i}}$ (figure 2$)$ or $\mathrm{p}_{\mathrm{i}}=\mathrm{S}_{\mathrm{i}}-(1 / \mathrm{Si}) \mathrm{Q}_{\mathrm{i}}$ (figure 3$)$ that new results are obtained.

The main effect of these inverse demand curves is to heighten the importance of both market size and environmental regulations. Importantly, the cut-off points for firm 1 either to cease exporting to country $B\left(e>S_{B} / 2-\right.$ $\mathrm{t}$ ), or to cease production entirely $\left(e>\mathrm{S}_{\mathrm{A}} / 2+\mathrm{t} / 2\right)$ now depend on the market size (the upward sloping

Figure 2

Optimal location choice for parameter values

$S_{A}=S_{B} ; t=0.3 ; F_{A}=0 ; F_{B}=1, p_{i}=S_{i}-Q_{i}$.

${ }^{2}$ For e $<1 / 2$-t firn firm 1 only sells the transportation

Optimal Location Choice

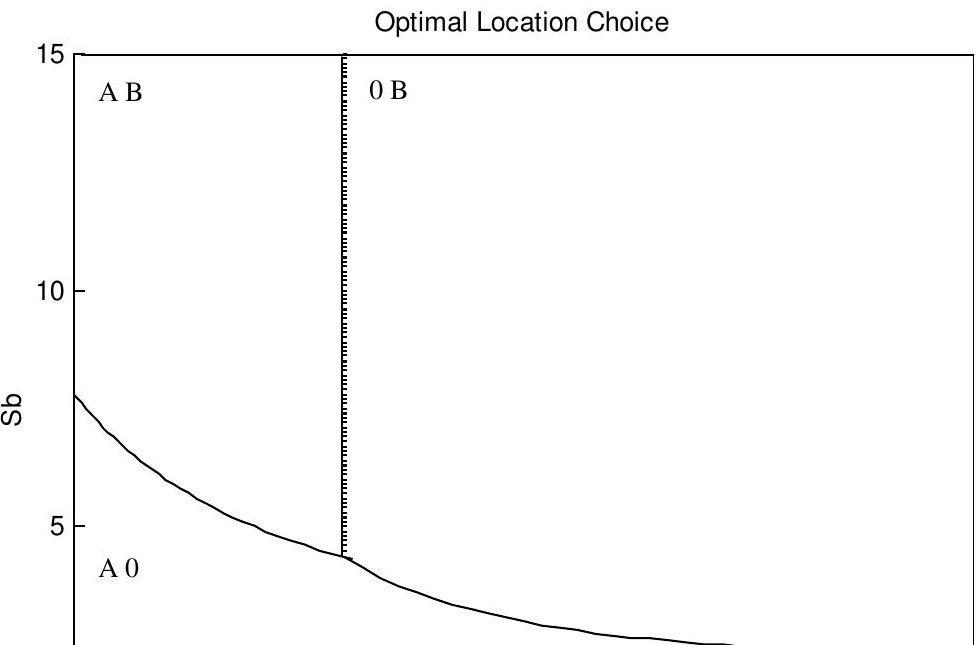

$2-\mathrm{t} \leq \mathrm{e}<1 / 2+\mathrm{t} / 2$ suntry $\mathrm{B}$ due to 
Figure 3

Optimal location choice for parameter values $S_{A}=S_{B} ; t=0.3 ; F_{A}=0 ; F_{B}=1, p_{i}=S_{i}-\left(1 / S_{i}\right) Q_{i}$.

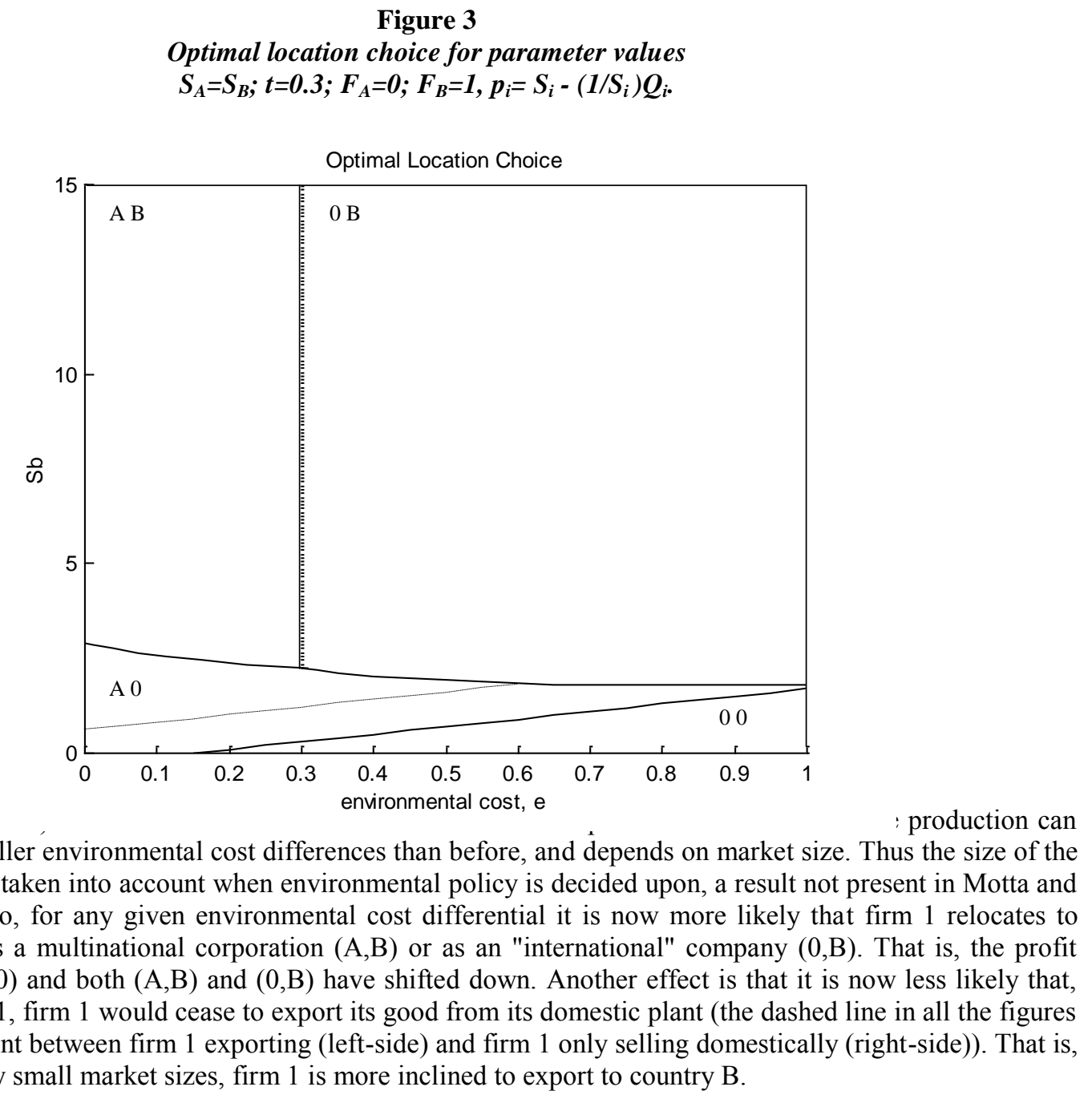

lines in figures 2

Figure 4 
Optimal location choice for the case $p_{i}=S_{i}$ - (1/Si) Qi for parameter values

$S_{A}=S_{B} ; F_{A}=0 ; F_{B}=1$.

Dashed lines represent $t=0.1$ and solid lines represent $t=0.3$. For clarity $S_{B}$ is restricted to be between 0 and 5 .

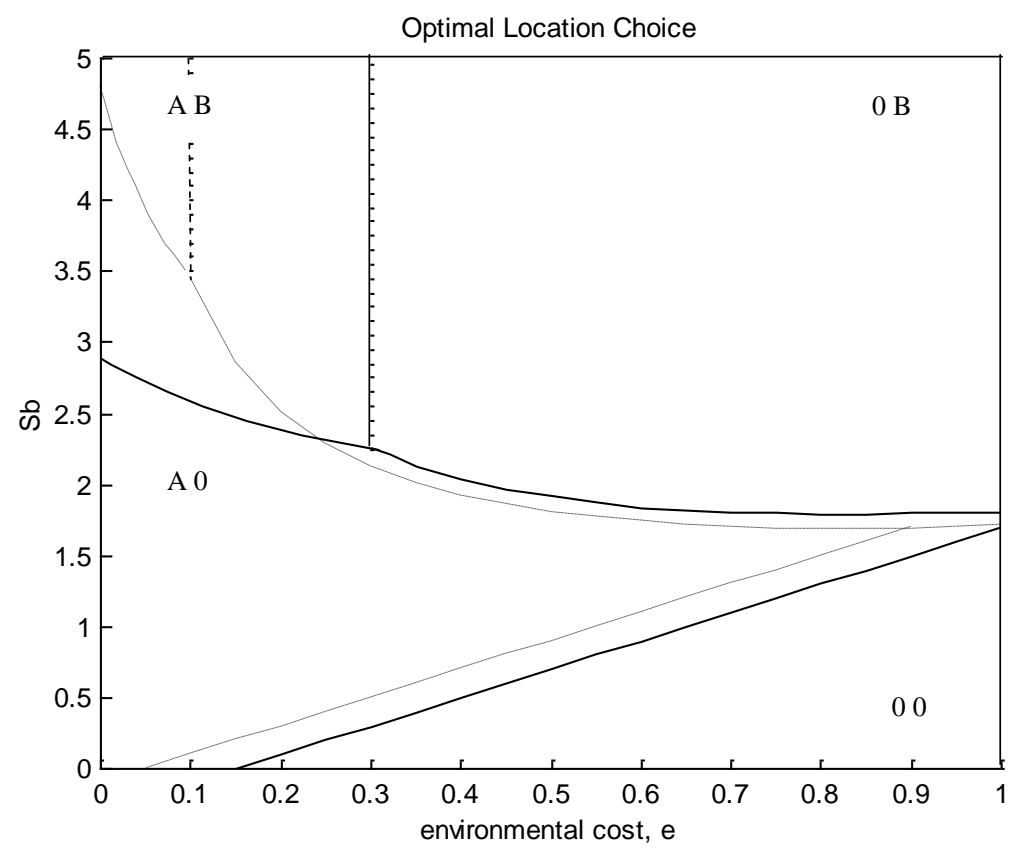

However, in addition to these new results, we also have that the essential trade off between environmental costs and market size is similar to figure 1. For example, in all three figures we have that, as market size increases (of both countries) firm 1 is more likely to move to country B, no matter what the environmental cost difference is. In these cases firm 1 is compelled to take advantage of the lower marginal cost of production in country B. However, even at environmental cost harmonization $(\mathrm{e}=0)$, firm 1 would eventually move production since average cost in B is lower as fixed costs are spread over more production units, thus outweighing the cost of transportation. Again, the difference is that such relocation by firm 1 will occur at a relatively smaller market size compared to Motta and Thisse (1994). Also, for any given market size, firm 1 is more likely to leave location (A,0) as environmental regulations become more stringent; for small markets firm 1 shuts down its operation, at large market sizes firm 1 relocates to country $B$. At very large market sizes, say $S_{B}=12$, the parameterization of the inverse demand function has no impact; whenever e is greater than $\mathrm{t}$ firm 1 will cease to be a multinational firm and become a purely "international" firm. This is a result of our assumption that $\mathrm{F}_{\mathrm{A}}=0$ in these figures (see figure 5).

\section{Figure 5}

Optimal location choice for the case $p_{i}=S_{i}-(1 / S i)$ Qi for parameter values $S_{A}=S_{B} ; t=0.1 ; F_{B}=1$.

Dashed lines represent $F_{A}=0.7$ and solid lines represent $F_{A}=0$. For clarity $S_{B}$ is restricted to be between 0 and 5 .

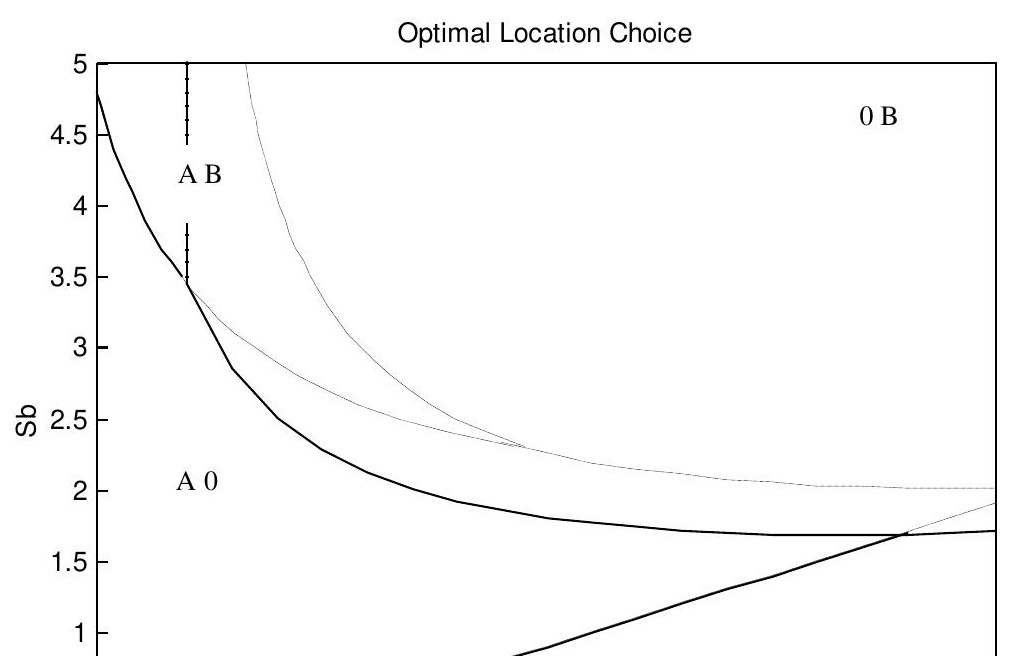


Since the result that market size may affect trade patterns and firm location is significant, we continue our discussion in terms of case (3) where market size is allowed to affect both the intercept and the slope of the inverse demand curve. Under this assumption we conduct comparative statics for the various parameters: tariff rates, fixed costs, and relative market size. ${ }^{3}$ Suppose first that the trade barrier (consisting of transportation costs and artificial barriers such as tariffs) is lowered; for example, the two countries engage in mutual lowering of tariffs among themselves (free trade area). A reduction of the barriers to trade encourages firm 1 to produce in a single location to take advantage of economies of scale; the $(\mathrm{A}, \mathrm{B})$ choice becomes less favorable compared to $(0, \mathrm{~B})$ as well as compared to $(A, 0)$, see figure 4 . That is, the borders between $(A, B)$ and both $(A, 0)$ and $(0, B)$ move north-east. Thus the main effect is that the region where firm 1 operates as a multinational corporation is significantly reduced. Also, perhaps surprisingly, firm 1 is more likely to shut down production at small market sizes and high environmental costs (region $(0,0)$ is enlarged) since the lower tariff rate intensifies competition from abroad (that is, firm 2 exports from country B replaces some firm 1 production). An intuitive finding is that for low environmental costs firm 1 is not as likely to move to country $B$ (a reversal of location from $(A, B)$ to $(A, 0)$ ), while at high environmental costs firm 1 is more likely to move to country $\mathrm{B}$ (choose $(0, \mathrm{~B})$ over $(\mathrm{A}, 0)$ ). This is explained by the fact that at small differences in marginal costs, it is better for firm 1 to avoid the fixed costs and take advantage of the low export costs. Conversely, at large differences in costs, firm 1 is better off to absorb the fixed cost and ship its products from country B.

If we stay with low trade barriers, but instead explore the effect of additional fixed costs for producing in country B for exports to country A, then the optimal location choice can be seen in figure 5 . These endogenous fixed cost are structured here so that there are still scale economies, but less so than before; in particular, $F_{B}$ is still equal to 1 while $\mathrm{F}_{\mathrm{A}}$ is now equal to 0.7 (thus fixed costs are higher but not twice as high). The effects on firm 1's location decision is predictable since it is less likely that firm 1 completely relocates to country B. Firm 1 prefers to remain in country A for a greater range of market size and environmental costs. Both region $(\mathrm{A}, 0)$ and $(\mathrm{A}, \mathrm{B})$ expand at the expense of $(0, B)$. In fact, even for relatively high environmental costs, firm 1 prefers to supply its domestic market from its existing plant due to both higher fixed costs and trade costs (here $t$ is quite low). However, as market size becomes large, firm 1 still maximizes its profit by moving to country B. In this case the size of the market lowers average cost sufficiently to overcome both trade barriers and high fixed costs associated with producing in B for exports.

We also explore the effect of different relative market size under the assumption of low trade costs and $\mathrm{F}_{\mathrm{A}}=0$. Figure 6 shows the optimal location choice when changing relative market sizes from equality $\left(\mathrm{S}_{\mathrm{A}}=\mathrm{S}_{\mathrm{B}}\right)$ to $\mathrm{S}_{\mathrm{A}}=2.74 \mathrm{~S}_{\mathrm{B}}$, so that the home country (A) is 2.74 times larger than country B. ${ }^{4}$ The main effect is the expansion of region $(0, \mathrm{~B})$. This is curious since one might imagine that with a large market, country A (the larger market) would be more attractive as a production location. However, the dominant effect is instead that firm 1 has an even greater incentive to produce at a low marginal cost when supplying the larger market (and fixed cost becomes less

\footnotetext{
${ }^{3}$ To compare the effects from parameter changes for $\mathrm{p}_{\mathrm{i}}=1-\left(1 / \mathrm{S}_{\mathrm{i}}\right) \mathrm{Q}_{\mathrm{i}}$ see Motta and Thisse (1994).

${ }^{4}$ We choose 2.74 because of the relative size of Mexico and the U.S. (in terms of population) as discussed in the next section.
} 
important). ${ }^{5}$ This effect is reduced if tariff rates are higher. A large market also makes is less likely that firm 1 would decide to stop producing completely, region $(0,0)$ becomes smaller.

\section{Figure 6}

Optimal location choice for the case $p_{i}=S_{i}-(1 / S i)$ Qi for parameter values $t=0.1 ; F_{B}=1 ; F_{A}=0$. The solid lines represent $S_{A}=S_{B}$, while the dashed lines represent $S_{A}=2.74 S_{B}$.

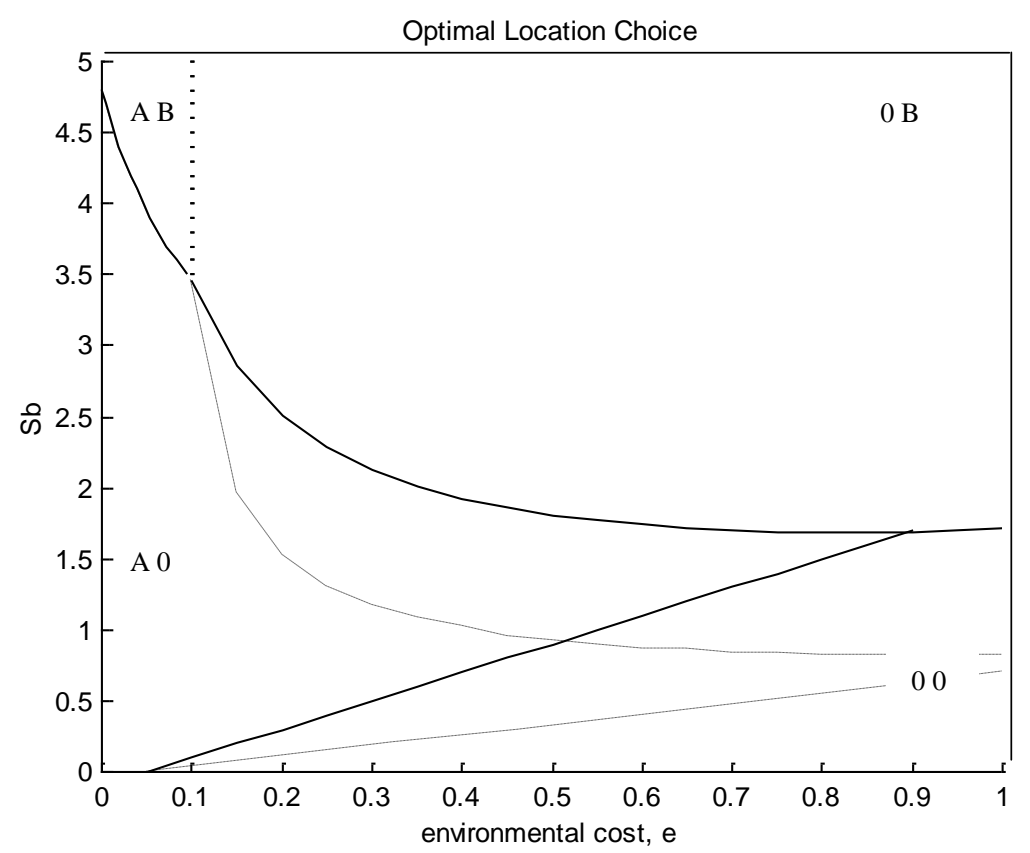

\section{U.S. - Mexico Free 1 laue}

The implementation of the North American Free Trade Agreement (NAFTA) in January 1994 provides an illustrative application of our model. The model is applicable to this recent regional trade agreement since we can represent the U.S.-Mexico agreement as lower tariff barriers combined with lower fixed cost of establishing a plant in Mexico (here fixed costs are loosely defined, covering some aspect of risk, say, the risk of nationalization). Thus we combine lower tariff rates $(t)$ with lower fixed costs $\left(F_{B}\right)$ in the model. The market size of the U.S. is of course much greater than that of Mexico. Although market size is an ambiguous measure, we choose the number 2.74 (figure 6) because in the year 2000, the population size of the U.S. was 2.74 times greater than that of Mexico. In alternative calibrations we used relative size of GDP, 10.69, and relative per capita GDP, 3.99, using purchasing power parity adjusted numbers. These numbers gave qualitatively the same results as 2.74 , although all effects are magnified. Of course, our stylized model abstracts from several realistic considerations. For example, Mexico began lowering trade barriers and unilaterally relaxed barriers to foreign direct investment in the early 1990s and U.S. tariffs would have been lowered anyway due to Uruguay Round. Also, Mexico's severe recession in 1995 and the drastic devaluation of the Peso are all complications that cannot be fully reflected in a static model. Despite these limitations, we still find it instructive to explore the model's predictions for NAFTA.

Table 1. Foreign Direct Investment and Trade between the US and Mexico (million \$)

\begin{tabular}{|l|c|c|c|c|c|c|}
\hline Year & $\begin{array}{c}\text { USDIA: D.I. } \\
\text { position* }\end{array}$ & $\begin{array}{c}\text { Annual growth } \\
\text { rate (\%)** }\end{array}$ & $\begin{array}{c}\text { FDIUS: } \\
\text { Mexico to US } *\end{array}$ & $\begin{array}{c}\text { US Exports to } \\
\text { Mexico }\end{array}$ & $\begin{array}{c}\text { US Imports } \\
\text { from Mexico }\end{array}$ & $\begin{array}{c}\text { Net Exports US } \\
\text { deficit (-) }\end{array}$ \\
\hline
\end{tabular}

\footnotetext{
${ }^{5}$ If $F_{A}$ is kept at 0.7 then the effect is to make $(0, B)$ less attractive compared to $(A, 0)$ and $(A, B)$. However, the impact is not very large.
} 


\begin{tabular}{|l|l|l|l|l|l|l|}
\hline 1970 & 1,912 & --- & & & & \\
\hline 1975 & 3,200 & 10.8 & & & & \\
\hline 1980 & 5,986 & 13.3 & & & & \\
\hline 1985 & 5,417 & -2.0 & & 13,635 & 19,132 & $-5,497$ \\
\hline 1990 & 10,313 & 13.7 & 575 & 28,279 & 30,157 & $-1,878$ \\
\hline 1991 & 12,501 & 21.2 & 747 & 33,277 & 31,130 & 2,147 \\
\hline 1992 & 13,730 & 9.8 & 1,406 & 40,592 & 35,211 & 5,381 \\
\hline 1993 & 15,221 & 10.9 & 1,244 & 41,581 & 39,917 & 1,664 \\
\hline 1994 & 16,968 & 11.5 & 2,069 & 50,843 & 49,494 & 1,349 \\
\hline 1995 & 16,873 & -0.6 & 1,850 & 46,292 & 62,101 & $-15,809$ \\
\hline 1996 & 19,351 & 14.7 & 1,641 & 56,761 & 72,963 & $-16,202$ \\
\hline 1997 & 24,050 & 24.3 & 3,244 & 71,378 & 85,830 & $-14,452$ \\
\hline 1998 & 28,396 & 18.1 & 2,432 & 79,010 & 94,709 & $-15,699$ \\
\hline 1999 & 34,265 & 20.7 & 3,612 & 86,866 & 109,706 & $-22,840$ \\
\hline
\end{tabular}

* Measured at a historical-cost basis

** Annual growth rate $=\exp (\ln ($ Year2/Year1 $) / t)-1$, where $\mathrm{t}=$ Year2-Year1

Source: US Department of Commerce

From 1993 to 1999 U.S. exports to Mexico grew by over 100\% and U.S. imports from Mexico grew by almost 200\% (see Table 1). Although these numbers are influenced by the Mexican Peso crisis, they also reflect the influence of NAFTA. On average, the applied tariff levels in the U.S. and Mexico have fallen from 10\% and 2.07\% in 1993 to $2.9 \%$ and $0.65 \%$ in 1996, respectively (President, 1997), but part of the U.S. decline is due to the Uruguay Round. ${ }^{6}$ In terms of our model this change is represented by a fall in the t parameter. Due to the relatively minor change in tariff rates, many have characterized NAFTA as an investment agreement as opposed to a trade agreement. ${ }^{7}$ Thinking of NAFTA as facilitating U.S. investment translates into lower fixed cost $\left(\mathrm{F}_{\mathrm{B}}\right)$ in our model. In fact, prior to NAFTA much concern existed about American companies leaving the U.S. in favor of Mexico. In reality, the USDIA (U.S. Direct Investment Abroad) position could change in either way since prior to NAFTA Mexico had local manufacturing requirements (e.g. auto production) that meant that in order to sell some goods in Mexico they had to be produced locally. NAFTA would then reduce this kind of investment. However, lower tariffs for U.S. imports from Mexico combined with lower costs of moving production could translate into firms taking advantage of lower production costs and less stringent environmental requirements by establishing plants in Mexico. As Table 1 shows, the evidence shows a modest increase of foreign direct investment in both countries. However, as the Mexican economy expands after the recession in the mid-90s, further increases in direct investment might appear. Regardless, there has been a significant increase in U.S. investment in Mexico during the 1990s. For example, on a historical-cost basis U.S. investment in Mexico grew at an annual rate of $8.9 \%$ in the $70 \mathrm{~s}, 3.3 \%$ in the 80s (1982 financial crisis), and 12.8\% in the 90s (1995 financial crisis).

In terms of environmental regulation in both the U.S. and Mexico several changes have been made in the last decade. In the U.S. the cost of environmental protection for businesses has increased significantly as can be seen in Table 2. Thus there might be an incentive for U.S. firms to relocate in order to avoid these added costs, especially in the hardest hit sectors: Chemicals and Allied Products, Petroleum and Coal Products, Paper and Allied Products, and Primary Metal Products (U.S. Bureau of the Census). However, whether they move to Mexico depends on the stringency of Mexican environmental laws. Although previously being much less stringent, today Mexico's environmental laws are very similar to U.S. laws. The difference therefore lies in the enforcement of those laws. Thus although there are no doubt benefits with respect to lower environmental cost in Mexico today, it is less clear what the difference will be in the future. In fact, the initial indications are that the difference in terms of environmental costs will be reduced. In our model this would mean a leftward movement along the e-axis. However, if Mexico were to reduce enforcement efforts to attract investment, then a rightward movement would be seen.

\footnotetext{
${ }^{6}$ The relatively greater increase in American imports is due to a relatively greater change in tariffs in this direction, a stronger dollar, and a reduction in Mexican domestic demand after the recession.

${ }^{7}$ For example, Ross Perot writes: "NAFTA's principal goal is to protect the investment of U.S. companies that build factories in Mexico. This is accomplished by reducing the risk of nationalization, by permitting the return of profits to U.S. businesses, and by allowing unlimited access to the American markets for goods produced in Mexico." (Perot and Choat, 1993).
} 
Table 2. Pollution Abatement Costs in the US (million \$)

\begin{tabular}{|c|c|c|c|}
\hline Year & $\begin{array}{l}\text { PACE } \\
\text { (Total) }\end{array}$ & $\begin{array}{c}\text { PAOC } \\
\text { (Operating Costs) }\end{array}$ & $\begin{array}{c}\text { Annual growth rate } \\
\text { of PAOC }(\%)\end{array}$ \\
\hline 1973 & 4,799 & 2,445 & --- \\
\hline 1974 & 6,204 & 3,103 & 26.9 \\
\hline 1975 & 7,300 & 3,662 & 18.0 \\
\hline 1976 & 8,071 & 4,539 & 23.9 \\
\hline 1977 & 8,909 & 5,425 & 19.5 \\
\hline 1978 & 9,644 & 6,328 & 16.6 \\
\hline 1979 & 11,064 & 7,462 & 17.9 \\
\hline 1980 & 11,751 & 8,209 & 10.0 \\
\hline 1981 & 12,595 & 9,110 & 11.0 \\
\hline 1982 & 11,589 & 8,565 & -6.0 \\
\hline 1983 & 11,970 & 9,925 & 15.9 \\
\hline 1984 & 13,060 & 10,888 & 9.7 \\
\hline 1985 & 14,488 & 11,678 & 7.3 \\
\hline 1986 & 15,105 & 12,258 & 5.0 \\
\hline 1987 & N/A & $\mathrm{N} / \mathrm{A}$ & --- \\
\hline 1988 & 17,432 & 14,009 & --- \\
\hline 1989 & 19,935 & 15,626 & 11.5 \\
\hline 1990 & 23,102 & 17,071 & 9.2 \\
\hline 1991 & 24,777 & 17,287 & 1.3 \\
\hline 1992 & 27,621 & 19,228 & 11.2 \\
\hline 1993 & 26,397 & 18,799 & -2.2 \\
\hline 1994 & 28,549 & 20,669 & 9.9 \\
\hline
\end{tabular}

Source: US Bureau of Census, Current Industrial Reports

Finally, the ultimate purpose of NAFTA is to provide strong growth for both the U.S. and Mexico (and Canada) over time. Thus, although we don't know what will happen to the relative size of the two countries, they ought to become larger in the future. This means that in our model we will continually move up the $S_{B}$-axis (where $\mathrm{S}_{\mathrm{B}}$ represents the size of the Mexican economy).

As discussed above, the free trade agreement signed between the U.S. and Mexico can fruitfully be described in our model as a lowering of $\mathrm{t}, \mathrm{F}_{\mathrm{B}}$, and an increase market size. It is unclear what the effect will be on environmental cost differentials, but the side agreements accompanying NAFTA predicts less differences in the coming years. There are of course severe limitations in taking a simple model and fitting it to a complicated bilateral trade agreement. First, the picture shows a static world, but we want to impose a dynamic scenario upon it. Second, to be able to predict anything for the future we need to know where we are today in terms of market size, environmental policy differentials, and other model parameters. Unfortunately these things are not known in our abstract model. Third, there is a great continuum of U.S. firms all with different production cost, both in terms of environmental costs and labor costs and they would all react differently to NAFTA. Despite these limitations of the model, we attempt to provide a story in figure 7.

\section{Figure 7}

Optimal location choice for the case $p_{i}=S_{i}-(1 / S i)$

Qi for parameter values matching the US-Mexico experience.

We assume that $F_{A}=0$ and $S_{A}=2.74 S_{B}$, then due to economic integration both $t$ (from $t=0.45$ to $t=0.10$ ) and $F_{B}$ fall (from $F_{B}=1$ to $F_{B}=0.5$ ). In the diagram we go from solid to dashed lines.

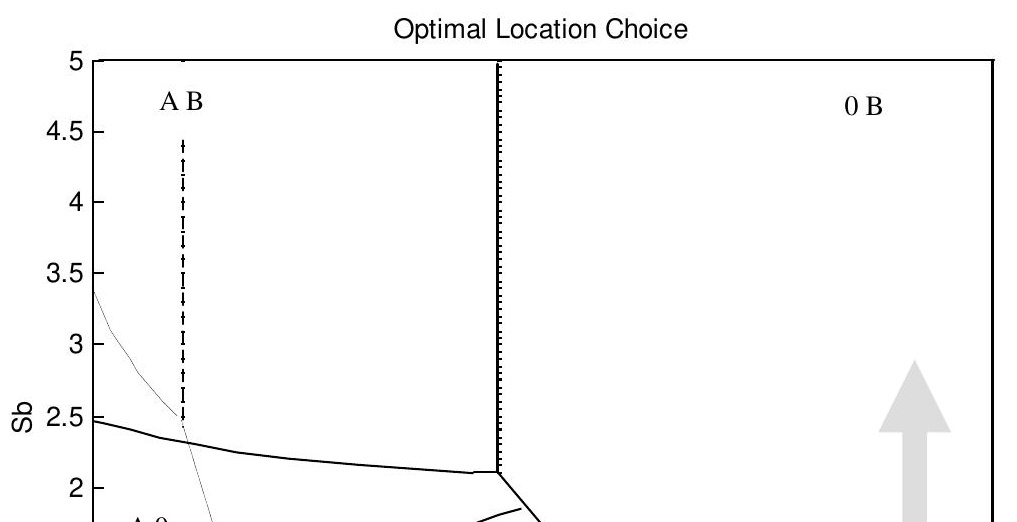


As a starting point, suppose the US and Mexico start out at market sizes represented by $S_{B}=1.5$ $\left(\mathrm{S}_{\mathrm{A}}=2.74 * 1.5\right)$ where one can imagine a spectrum of firms behaving in a variety of ways (see gray shaded area in figure 7). Within the shaded area there are firms located in the U.S. (country A) selling only in the U.S., firms located in the U.S. selling both in the U.S. and Mexico, and U.S. firms that operate in Mexico solely. Initially we assume that the solid lines represent the economic and regulatory climate, so that $\mathrm{t}=0.45$ (relatively high tariffs) and $\mathrm{F}_{\mathrm{B}}=1$ (relatively high fixed costs for locating in Mexico). Starting from these assumptions regarding parameters, and considering a given firm located within the gray area, we can explore the effect of economic integration (NAFTA) in this model. As stated above, it is reasonable to represent integration in this case by lower tariff barriers combined with lower fixed cost of establishing a plant in Mexico. Changing these two parameters then yield the picture represented by the dashed lines in figure 7. In this case the U.S. firm can only be of two kinds, depending on its level of environmental cost. ${ }^{8}$ If environmental costs are low, say for an American bank, the effect is that it remains in the U.S. and export its services to Mexico. For high environmental costs, say for a U.S. chemical plant, it is now more likely to relocate to Mexico and export their product back to America. Thus whether or not economic integration affects firm location depends on the relative magnitude of environmental costs. If the U.S. firm does not move, then the amount sold domestically will decline (more competition from the Mexican firm) while the amount exported to Mexico will increase (more competitive abroad with lower tariff rates). This is consistent with the trade data shown in Table 1 above. It is possible that U.S. firms decide to relocate to Mexico, but it is also possible that they all remain in the U.S. (provided that they initially produce domestically) and only export more to Mexico, a firm's relocation decision depends on the relative magnitude of environmental costs.

Over time two questions arise: what will happen to the size of these two markets and what will the future difference in terms of environmental policies be? The answer to the first question is relatively clear: over time the two economies are likely to grow (in terms of any variable - population, GDP, GDP per capita) as represented by an upward movement of the gray line. Thus increasing the likelihood, ceteris paribus, that a U.S. firm will move to Mexico. Note however, that for small environmental cost differences between the two countries, it is less likely that a U.S. firm would relocate. But if such relocation takes place, it is more likely that the U.S. firm shuts down its domestic plant and becomes an international firm. This is an important finding, if environmental cost differences are small then economic integration makes it less likely that a domestic firm would relocate production. But if such move takes place, then it is more likely that the firm ceases to produce domestically than prior to integration.

These effects must be balanced by future changes in environmental policies. The outcome of NAFTA in terms of environmental policy differences is less clear. On one hand we have the stated goal that Mexico's policy will approach the U.S. (Mexican enforcement will catch up to the already written rules). On the other hand we have an often-stated belief that NAFTA could lead to a "race to the bottom;" in particular, that Mexico will keep

\footnotetext{
${ }^{8}$ Note, however, that if we started at a large market size and low environmental cost difference (say, $S_{B}=2.75$ and $\mathrm{e}=0.05)$, then economic integration actually brings U.S. firms back to America (from $(A, B)$ to $(A, 0)$ ).
} 
environmental rules lax in order to encourage foreign direct investment. If NAFTA rules prevail, then the U.S. will be better off in terms of production - facing a larger market and a lower cost of production relative to Mexico. Also, it is less likely that U.S. firms relocate. The environment will also be better off as Mexico adopts more stringent environmental laws. However, if Mexico were to lower its standards to attract investment, then perhaps Perot's "great sucking sound" come true as U.S. firms move production.

\section{Conclusions}

In a two-country, two-firm model of plant relocation we attempt to address the concern that more stringent environmental policies may lead to domestic firms relocating abroad. Building on Motta and Thisse (1994), we generalize their inverse demand function, which yield different equilibrium outputs that affects firm location in response to changing environmental policy. Although the qualitative effects on firm profit from changes in tariff rates, fixed costs, market size, and environmental policy differentials remain the same, several new results are obtained. The choice of parameter in the inverse demand function matters, and our framework shows a greater importance of both market size and environmental policy differences across countries. In particular, for relatively small countries domestic firms location choices depends on market size; slightly more stringent environmental policies could lead to major changes in export patterns and in the viability of the domestic industry. The modifications are not only realistic extensions to the Motta and Thisse (1994) framework, but also allow for an opportunity to employ the model when analyzing the environmental provisions of a bilateral trade treaty, such as the U.S.-Mexico North American Free Trade Agreement (NAFTA) on industry relocation.

In terms of economic integration, we confirm the Motta and Thisse (1994) result that firm relocation is less likely if one includes fixed costs of establishing subsidiary abroad. But in addition to this intuitive result, we also show that the overall effect of economic integration is ambiguous. If economic integration is plausibly viewed as a combination of lower tariff rates and lower fixed costs of moving production abroad (reduced direct costs and reduced risk of relocation), then a firm may or may not initially relocate depending on environmental (marginal) cost of production. However, more interestingly, if environmental provisions accompany a bilateral trade agreement, it might actually be less likely that firms relocate after the economies are integrated. For the case of U.S.-Mexico, this result implies that we should not be surprised if firms do not move to Mexico en masse if the NAFTA side agreements regarding the environment are followed. However, as the two countries grow, ceteris paribus, we might expect more movement.

The simple model and its application to economic integration provide us with many possible issues worth further study. Further exploration of the effects of different functional forms for the inverse demand function may make the results more robust. By endogenizing the choice of environmental policy, perhaps by introducing another stage of the game where the government chooses its policy first, we might be able to explore countries' incentives to making environmental policies more or less stringent. Also, adding more firms within each country or by making a multi-country model would allow us to explore many issues that the simple model cannot address. For example, by building a three-country model we could explore what the effect might be on the non-integrating regions after preferential bilateral trade agreements are signed.

\section{References}

1. Beghin, J., Roland-Holst, D., and D. van der Mensbrugghe, 1994. "A Survey of the Trade and Environment Nexus: Global Dimensions," OECD Economic Studies, no. 23, pp. 167-192.

2. Leonard, J., 1988. Pollution and the Struggle for the World Product, New York: Miller Freeman Publications.

3. Low, P. and A. Yeats, 1992. "Do "Dirty" Industries Migrate?" in Low, P. (ed.), International Trade and the Environment, World Bank Discussion Papers 159, World Bank.

4. Low, P., 1992. "International Trade and the Environment: An Overview," in Low, P. (ed.), International Trade and the Environment, World Bank Discussion Papers 159, World Bank.

5. Lucas, R., Wheeler, D., and H. Hettige, 1992. "Economic Development, Environmental Regulation and the International Migration of Toxic Industrial Pollution: 1960-88," World Bank Discussion Papers 159, World 
Bank.

6. Markusen, J. R., Morey, E. R., and N. D. Olewiler, 1993. "Environmental Policy when Market Structure and Plant Locations are Endogenous," Journal of Environmental Economics and Management, 24, pp. 6986.

7. Motta, M. and J-F Thisse, 1994. "Does Environmental Dumping Led to Delocation?" European Economic Review, 38, pp. 563-576.

8. Perot, Ross and Pat Choat, 1993. Save Your Job, Save Our Country: Why NAFTA Must Be Stopped - Now! New York: Hyperion.

9. President of the US, 1997. "Study on the Operation and Effects of the North American Free Trade Agreement," July, Washington, D.C.

10. U.S. Bureau of the Census, Current Industrial Reports, Series MA-200, "Pollution Abatement Cost and Expenditures," Various years, Washington, D.C.

11. U.S. Department of Commerce, Bureau of Economic Analysis, data collected from their homepage at http://www.bea.doc.gov 